Note

\section{Fucoidan from Brown Seaweed Laminaria angustata var. longissima}

\author{
Keiko Kitamura, Masaru Matsuo \\ and Tsuneo YASUI \\ Institute of Applied Biochemistry, \\ University of Tsukuba, \\ Ibaraki 305, Japan
}

Received August 23, 1990

Fucoidans, polysaccharides mainly consisting of sulfated fucose, have been isolated and characterized from a variety of brown seaweeds. Anticoagulant activities of fucoidans from Eisenia, ${ }^{1}$ Ecklonia, ${ }^{2}$ and Hizikia ${ }^{3}$ have been reported. The brown alga Laminaria angustata var. longissima, which has been widely used as an edible seaweed in Japan, is expected to be cultivated artificially as a biomass resource. Occurrence of fucoidan in Laminaria ${ }^{4}$ has been known, but a purified fucoidan from $L$. angustata var. longissima, being electrophoretically homogeneous, has never been studied. This paper describes the purification of fucoidan from $L$. angustata var. longissima, its characterization, and its blood anticoagulant activity.

The alga, $L$. angustata var. longissima, which had been cultivated for one year (attaining a length of $6 \mathrm{~m}$ ) was harvested in September 1986 in Kushiro province, Hokkaido, and it was stored at $-20^{\circ} \mathrm{C}$ until use. The raw fronds $(26.7 \mathrm{~kg})$ containing $71.4 \%(\mathrm{w} / \mathrm{w})$ of water was chopped and extracted with distilled water (54 1) for $20 \mathrm{~min}$, and the residue was treated under the same conditions again. The residue was removed by filtration and two volumes of ethanol were added to the filtrate concentrated under reduced pressure. The resulting precipitate was washed and dried with ethanol and ether, successively, to give F-1 (191.8g). The yield of F-1 to the dried alga was about $2.6 \%(\mathrm{w} / \mathrm{w})$. About one third of the F-1 $(50 \mathrm{~g})$ was treated with calcium chloride solution and aqueous cetylpyridinium chloride (CPC), by the method of Anno et al.,${ }^{53}$ to give $\mathrm{F}-2(18.30 \mathrm{~g})$. The yield of F-2 to F-1 was about $36.6 \%(\mathrm{w} / \mathrm{w})$. A portion of $\mathrm{F}-2(1.0 \mathrm{~g})$ was fractionated by anion exchange chromatography on a column $(3.2 \times 45 \mathrm{~cm})$ of DEAE Toyopearl $650 \mathrm{M}$. The column was eluted with a linear gradient of $0.3-1.5 \mathrm{M}$ sodium chloride (2.0 1). The sugar content of each fraction $(20 \mathrm{ml})$ was measured by the phenol-sulfuric acid method using fucose as a standard (Fig. 1). The three major fractions (fraction tube numbers 42-43, 50-57, and 63-67) were dialyzed and lyophilized, to give F-3 $(0.02 \mathrm{~g}), \mathrm{F}-4$ $(0.82 \mathrm{~g})$, and F-5 $(0.06 \mathrm{~g})$. The yields of F-3, F-4, and F-5 to $\mathrm{F}-1$ were about $0.7 \%(\mathrm{w} / \mathrm{w}), 30.0 \%(\mathrm{w} / \mathrm{w})$, and $2.2 \%$ $(\mathrm{w} / \mathrm{w})$, respectively. The purification procedure of fucoidan from L. angustata var. longissima is shown in Fig. 2. The homogeneities of F-3, F-4, and F-5 were examined by electrophoresis on a cellulose acetate membrane under the following conditions: (a) $1.0 \mathrm{M}$ acetic acid-pyridine $(\mathrm{pH}$ 3.5) for $20 \mathrm{~min}$ at $0.5 \mathrm{~mA} / \mathrm{cm}$, (b) $0.2 \mathrm{M}$ calcium acetate for $3 \mathrm{hr}$ at $1.0 \mathrm{~mA} / \mathrm{cm}$, (c) $0.1 \mathrm{~N}$ hydrochloric acid for $2.5 \mathrm{hr}$ at $1.0 \mathrm{~mA} / \mathrm{cm}$. F-4, a purified fucoidan from $L$. angustata var. longissima, gave a single band in each condition as shown in Fig. 3, being electrophoretically homogeneous originally, and was used for further investigations.

The neutral sugar content was measured by GLC analysis of alditol acetate derivatives after acid hydrolysis using methyl- $\beta$-D-glucoside as a standard ${ }^{6)}$ and expressed as percentages of the dry weight. Fucose $(36.3 \%)$ and

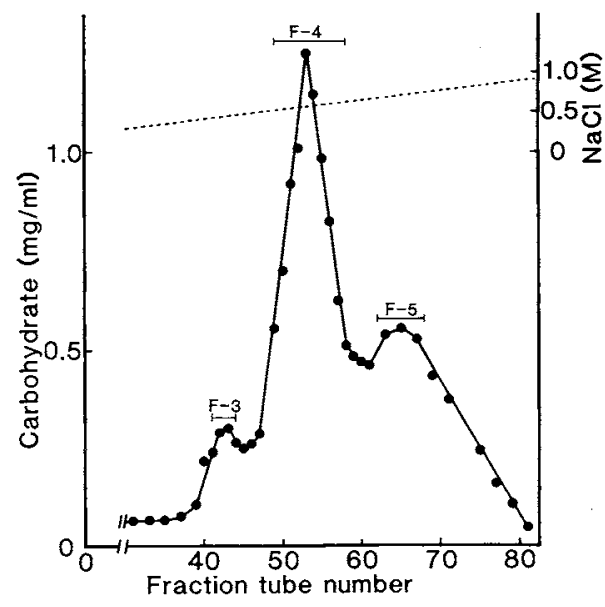

Fig. 1. Anion Exchange Chromatography of F-2 on DEAE Toyopearl 650M.

Sample $(1.0 \mathrm{~g})$ was put on the column $(3.2 \times 45 \mathrm{~cm})$ and eluted by a linear gradient of $0.3-1.5 \mathrm{M} \mathrm{NaCl}(2.01)$. Twenty milliliter fractions were collected and carbohydrates in the fractions were measured by the phenol-sulfuric acid method. Fraction tube numbers 42-43 (F-3), 50-57 (F-4), and $63-67$ (F-5), were combined. (-), carbohydrate $(\mathrm{mg} / \mathrm{ml}) ;(\cdots \cdots), \mathrm{NaCl}(\mathrm{M})$

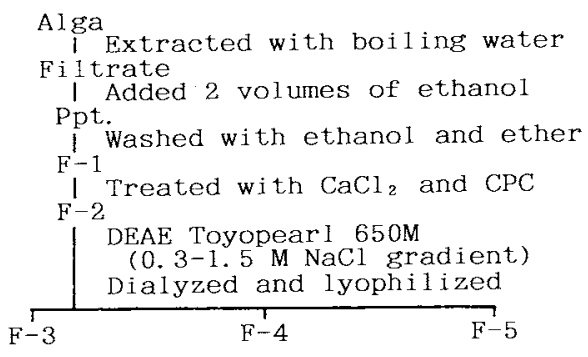

Fig. 2. Purification Procedure of Fucoidan from Laminaria angustata var. longissima. 


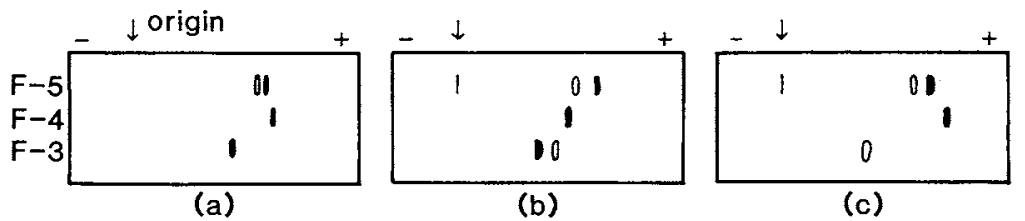

Fig. 3. Electrophoresis of F-3, F-4, and F-5 on a Cellulose Acetate Membrane.

(a) $1.0 \mathrm{M}$ acetic acid-pyridine ( $\mathrm{pH} 3.5$ ) for $20 \mathrm{~min}$ at $0.5 \mathrm{~mA} / \mathrm{cm}$; (b) $0.2 \mathrm{M}$ calcium acetate for $3 \mathrm{hr}$ at $1.0 \mathrm{~mA} / \mathrm{cm}$;

(c) $0.1 \mathrm{~N} \mathrm{HCl}$ for $2.5 \mathrm{hr}$ at $1.0 \mathrm{~mA} / \mathrm{cm}$.

galactose $(4.0 \%)$ were found in F-4, but xylose, mannose, glucose, and arabinose were not. The ratio of fucose to galactose was approximately $9: 1$. Uronic acid content $(0.7 \%)$ was negligibly small. An elemental analysis of F-4 gave the following data (Found: $\mathrm{C}, 21.8 ; \mathrm{S}, 8.50 ; \mathrm{N}, 0.10 \%$ ). A molar ratio of sulfate to sugar residues was calculated to be $0.88: 1$ from the elemental analysis. F-4 indicated a higher content of fucose and sulfate groups, with a lower content of galactose. The ratio fucose-galactose-sulfate $(9: 1: 9)$ of F-4 resembled those of the fucoidans from Pelvetia $^{5)}$ and Ecklonia. ${ }^{2)}$ The $[\alpha]_{\mathrm{D}}$ of F-4 showed to be $-127.2^{\circ}$, indicating that the fucose residues were predominant in the $\alpha-\mathrm{L}$ form. The strong absorptions observed at $1250 \mathrm{~cm}^{-1}$ and $850 \mathrm{~cm}^{-1}$ in I.R. spectrum of F-4 implied the presence of sulfate ester and the sulfate groups being in the axial position, ${ }^{7,8)}$ respectively. From the above results, most of the sulfate groups of F-4 seemed to be attached to the $\mathrm{C}-4$ position of fucose residues. Gel filtration chromatography to estimate the molecular weight of F-4 was done on a column of Sephacryl S-300 with $0.1 \mathrm{M}$ sodium chloride as eluent, using dextrans (MW $66,300,39,500$, and 10,400 ) as standards. An approximate molecular weight was estimated to be $21,000-23,000$, which was smaller than those of fucoidans from Lessonia (MW 670,000), ${ }^{97}$ Ascoseira (MW 500,000) ${ }^{109}$ and Hizikia (MW $42,000$ and 95,000$)^{3)}$ and similar to that of the fucoidan from Ecklonia (MW 32,000 and 21,000). ${ }^{2)}$ Blood anticoagulant activity was measured by the method of Shimada et al. ${ }^{\left.1{ }^{1}\right)}$ using anti-thrombin activity with bovine thrombin. The anti-thrombin activity of F-4 was 200 units/mg, as compared with heparin (140 units/mg) commercially available as a standard. F-4, a purified fucoidan from $L$. angustata var. longissima, had an anticoagulant activity, which was similar to those of fucoidans from Eisenia, ${ }^{1)}$ Ecklonia, ${ }^{2)}$ and Hizikia. ${ }^{3)}$

Acknowledgments. We thank Hokkaido National Fisheries Research Institute of Fisheries Agency for the generous gift of the alga $L$. angustata var. longissima. This investigation was supported by Research Fund for "Biomass Conversion Planning" of the Ministry of Agriculture, Forestry and Fisheries of Japan.

\section{References}

1) T. Usui, K. Asari and T. Mizuno, Agric. Biol. Chem., 44, 1965 (1980).

2) T. Nishino, G. Yokoyama, K. Dobashi, M. Fujihara and T. Nagumo, Carbohyd. Res., 186, 119 (1989).

3) K. Dobashi, T. Nishino, M. Fujihara and T. Nagumo, Carbohyd. Res., 194, 315 (1989).

4) T. Fujikawa and K. Nakashima, Nippon Nogeikagaku Kaishi, 49, 455 (1975).

5) K. Anno, H. Terahata, Y. Hayashi and N. Seno, Agric. Biol. Chem., 30, 495 (1966).

6) I. Kusakabe, Y. Kamiyama and T. Yasui, Nippon Nögeikagaku Kaishi, 51, 167 (1977).

7) A. G. Lloyd, K. S. Dodgson, P. G. Price and F. A. Rose, Biochim. Biophys. Acta, 46, 108 (1961)

8) A. G. Lloyd and K. S. Dodgson, Biochim. Biophys. Acta, 46, 116 (1961).

9) E. Percival, M. F. Venegasjara and H. Weigel, Phytochemistry, 22, 1429 (1983).

10) P. Finch, E. Percival, I. R. Slaiding and H. Weigel, Phytochemistry, 25, 443 (1986).

11) K. Shimada, M. Igarashi and T. Asada, J. Med. Soc. Toho, 18, 939 (1971). 